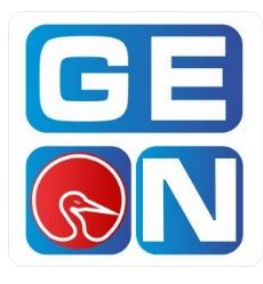

Revista GEON (Gestión, Organizaciones y Negocios.) ISSN: 2346-3910 en línea revistageon@unillanos.edu.co Universidad de los Llanos Colombia

Torres-Flórez, Dagobertoi.

\title{
La investigación social proceso de seguimiento
} continuo

Revista GEON, Vol. 4, No. 2, 2017

Pág. 5

Disponible en: $\underline{\text { https://doi.org/10.22579/23463910.19 }}$

\footnotetext{
${ }^{\mathrm{i}}$ https://orcid.org/0000-0002-7925-3005
}

Esta publicación se encuentra bajo licencia: Creative Commons

ReconocimientoNoComercialSinObraDerivada 4.0 Internacional

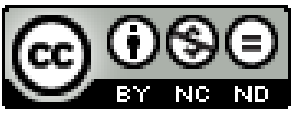

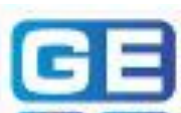
QN

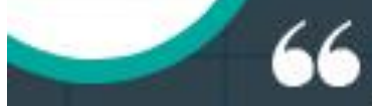

Las investigaciones sociales están en la búsqueda de cómo evitar la percepción, la desconfianza con el uso de los datos, y sobre todo como puede retribuir a la población estudiada
RevistaGEON

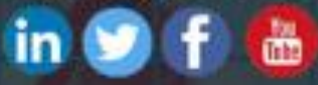




\section{EDITORIAL}

\section{La investigación social proceso de seguimiento continuo por Dagoberto Torres Flórez}

Hablando de investigación como algo reflexivo, sistemático, controlado y crítico, hace que quien se involucra en estas tareas lo haga en forma planeada y organizada, por ello definido el problema, se investiga y se lleva a una respuesta que permita solucionar el problema, sin embargo, todo esto lo podemos desarrollar con las palabras pregunta a ejemplo: el qué (tema o cuestión), para que (objetivo), por qué (problema), dónde (área), cuándo (cronograma), quienes (equipo de trabajo), con qué (financiación).

Al iniciar, es la formulación del problema la que nos va a marcar la ruta, que permitirá planear la investigación para que nos lleve a un resultado óptimo, por ello es importante formularlo en un enunciado que responda de manera clara, precisa y concreta el qué y para qué. En esta planeación delimitar el tema y campo de investigación ayuda a que se comprenda el alcance tanto en posibles resultados, como magnitud del tiempo necesario para su ejecución.

Antes de proponer el para qué, se sugiere al investigador revisar la literatura, conocer información al respecto, revisar el estado del Arte de la temática a indagar, como elementos históricos, informes, tendencias, documentos oficiales, fuentes estadísticas, referencias bibliográficas, publicaciones periódicas, libros y todos aquellos elementos que nos permitan avanzar en paso firme hacia el planteamiento de los objetivos que enmarcaran el norte de la investigación y que ayudarán a la elección de la metodología.

Luego de planear la investigación, es necesario organizarla para ello el diseño de la investigación como aquellos pasos y actividades que permitirán guiar la investigación a obtener los resultados esperados. Elementos como el marco de referencia como la información necesaria que le permitirá al investigador tener claridad sobre la información relevante para el desarrollo de la investigación, definir el equipo, que instrumentos y técnicas se utilizarán, determinar la población y la muestra como foco de investigación.

$\mathrm{Al}$ ejecutar es el trabajo de campo el que logra aclarar que lo planeado y lo organizado realmente ayudará a conseguir los resultados esperados, sin embargo es este paso el que debe contar con una flexibilidad pero sin perder la focalización hacia los objetivos, a su vez el organizar, analizar e interpretar los datos deben llevar al investigador a mantener la objetividad, respetar la información que llego y salvaguardar para que no sea utilizada con otros fines, pues se construyen a partir de datos individuales, las investigaciones sociales están en la búsqueda de cómo evitar la percepción, la desconfianza con el uso de los datos, y sobre todo como puede retribuir a la población estudiada.

\author{
Dagoberto Torres Flórez \\ Director - Editor Revista GEON \\ @ dagoto \\ @ RevistaGEON
}

¡Animo! a escribir

\section{Referencias}

Cook, T. D., \& Reichardt, C. S. (2005). Métodos

cualitativos y cuantitativos en

investigación. Madrid: Ediciones Morata. 